$r_{e}$ ALA

IV. Autores 

REALA. Revista de Estudios de la Administración Local y Autonómica nos 313-314, mayo-diciembre 2010, pp. 307-309 ISSN: 1699-7476

\section{MAGALDI, Nuria}

Doctora en Derecho con mención europea y premio extraordinario (Universidad de Barcelona, 2010), licenciada en Ciencias Políticas y de la Administración (Universidad de Barcelona, 2006), LL.M. (Universität Greifswald, Alemania, 2002).

Ha realizado diversas estancias de investigación en Alemania e Italia (Heidelberg, Frankfurt, Florencia, Viterbo, Greigfswald), becada por diversas instituciones públicas y privadas (Fundación La Caixa, DAAD -servicio de intercambio cultural alemán-, Max Planck Institut für ausländisches öffentliches Recht und Völkerrecht, Institut d'Estudis Autonòmics).

Sus principales líneas de investigación son los servicios públicos locales y la iniciativa económica local, las obligaciones lingüísticas en las relaciones comerciales y de consumo y el derecho de acceso a documentos y archivos públicos. Es autora de dos monografías y varios artículos de revista y capítulos de libro sobre estas materias.

\section{MARCOU, Gérard}

Profesor Agregado de Derecho Público en la Universidad de París I PanthéonSorbonne desde septiembre de 1998. Director del Grupo de Interés Científico "Groupement de Recherche sur l'Administration Locales en Europe" (GRALE). Director de la Colección “Logiques juridiques” de la Editorial l'Harmattan en París. Ha impartido cursos en diversas universidades europeas y latinoamericanas. Es experto en temas locales comparados y forma parte como tal de numerosos organismos nacionales e internacionales. Es autor de un importante número de publicaciones sobre Urbanismo y Administraciones Locales y Territoriales.

\section{LÓPEZ RAMÓN, Fernando}

Zaragoza, 1953. Catedrático de Derecho Administrativo en la Universidad de Zaragoza con cinco sexenios de investigación reconocidos. Tras seguir la carrera de Derecho en la Universidad de Zaragoza y obtener el Primer Premio Extraordinario (1975), se doctoró en la Universidad de Bolonia, logrando también el Primer Premio del Doctorado (1978). Desarrolló su carrera académica bajo la dirección de su maestro, el profesor Lorenzo Martín Retortillo, hasta obtener la Cátedra de Derecho Administrativo en la Universidad de Barcelona (1986). Después regresó a la Universidad de Zaragoza (1988), de cuya Facultad de Derecho ha sido Decano (2000-2003). Profesor invitado en diversas universidades españolas y extranjeras, ha sido experto del Consejo 
de Europa, coordina el Master en Urbanismo y el Observatorio de Políticas Ambientales, dirige la Revista Aragonesa de Administración Pública, y preside la Fundación Ecología y Desarrollo. Ha obtenido premios nacionales de investigación en materia de vivienda (1980) y defensa nacional (2006). Autor de gran número de publicaciones en materias de su especialidad, cabe destacar entre sus libros: La protección de la fauna en el Derecho español (1980), La conservación de la naturaleza: los espacios naturales protegidos (1980), La caracterización jurídica de las Fuerzas Armadas (1987), Estudios jurídicos sobre ordenación del territorio (1995), Principios de Derecho Forestal (2002), La autonomía de Aragón (2005), Introducción al Derecho Urbanístico ( $3^{\mathrm{a}}$ ed., 2009) y Política ecológica y pluralismo territorial (2009).

\section{TOSCANO GIL, Francisco}

Profesor contratado Doctor de Derecho Administrativo de la Universidad Pablo de Olavide de Sevilla. Doctor en Derecho por esta Universidad, con Premio Extraordinario de Doctorado. Autor de diversas publicaciones en materia de régimen local, entre las que cabe destacar el libro "Autonomía y potestad normativa local” (Comares, 2006), que fue Premio Nacional Fernando Albi a Estudios sobre Administración Local, así como sus últimas publicaciones, "El fenómeno metropolitano y sus soluciones jurídicas" (Iustel, 2010), y “Los consorcios metropolitanos” (Fundación Democracia y Gobierno Local, IAAP, 2011).

\section{GARCÍA-CALABRÉS COBO, Francisco}

Doctor en Derecho por la Universidad de Córdoba (2005) y profesor interino de Derecho Internacional Privado de la Facultad de Derecho de la Universidad de Córdoba desde 2006. Diplomado Superior en Criminología por la Universidad Complutense de Madrid (1988). Abogado en ejercicio y Defensor de la Ciudadanía de la provincia de Córdoba (2005-2011). Además ha sido fundador y vicepresidente de la Comisión de Derecho de Extranjería del Ilte. Colegio de Abogados de Córdoba y Director del Centro de Menores Inmigrantes “Despertares”. Especialista en Mediación y Arbitraje.

Ha publicado 11 libros entre los que destaca "Inmigrantes en España. Claves para comprender un fenómeno mundial” (Laberinto, 2009), "La extranjera. Estudio de la Inmigración femenina en España” (Junta de Andalucía, 2004) o "Régimen Laboral de los Trabajadores Extracomunitarios" (Junta de Andalucía, 2006). Entre los artículos científicos publicados destacan "Mirada retrospectiva a la legislación italiana sobre inmigración” (Rev. Dcho. Migratorio y Extranjería-Lex Nova, n²6), "La enésima reforma de la Ley de Extranjería” (Rev. Fomento Social-INSA ETEA, n 65), “¿Menor inmigrante o menores inmigrantes? Diferencias de régimen jurídico” (Cuadernos Digitales de Formación-CGPJ, volumen 10), o la "Inmigración en el corazón de Europa: Alemania y Francia” (Rev. Gral. Dcho. Comparado-Iustel, $n^{\circ} 65$ ). Integrante del Grupo 308 de Investigación SEJ-423 de Derecho Internacional Privado Europeo. 


\section{PALAZZI, Francesca}

Doctora de Derecho Público por la Universidad de Bolonia, con una Tesis Doctoral titulada "Principi e dinamiche dei conferimenti di funzioni amministrative agli enti locali dopo la riforma del titolo V della Costitutizone”. Funcionaria de la Región Emilia-Romagna. Autora de diversas publicaciones en materia de régimen local, y en particular sobre las ordenanzas del convivencia urbana en el sistema administrativo italiano. 
